ABOUT THE SERIES

Latin America Otherwise: Languages, Empires, Nations is a critical series. It aims to explore the emergence and consequences of concepts used to define "Latin America" while at the same time exploring the broad interplay of political, economic, and cultural practices that have shaped Latin American worlds. Latin America, at the crossroads of competing imperial designs and local responses, has been construed as a geocultural and geopolitical entity since the nineteenth century. This series provides a starting point to redefine Latin America as a configuration of political, linguistic, cultural, and economic intersections that demands a continuous reappraisal of the role of the Americas in history, and of the ongoing process of globalization and the relocation of people and cultures that have characterized Latin America's experience. Latin America Otherwise: Languages, Empires, Nations is a forum that confronts established geocultural constructions, rethinks area studies and disciplinary boundaries, assesses convictions of the academy and of public policy, and correspondingly demands that the practices through which we produce knowledge and understanding about and from Latin America be subject to rigorous and critical scrutiny.

Beginning in the precolonial indigenous past, cultural symbols such as the Aztec mother earth goddesses have exerted a profound impact on the way women of Mexican descent have understood their sexuality and have imagined their roles within society and the family. Later history added other icons to the Aztec goddesses-namely, La Malinche, La Llorona, and the La Virgen de Guadalupe. Through legends, myths, and stories told to children and shared within communities and families, each of these fig- 
ures has influenced generations of individuals in the construction of their gender identities. This present work examines the way different groups of Chicana and U.S. Mexicana women have made use of these cultural symbols to negotiate, contest, and transform the forces that have confined or demeaned them. The women reimagine (or "transcode," to use Stuart Hall's term) the negative elements attached to these figures and assign them new meanings as part of a struggle for self-empowerment and to defeat racial stereotypes and discrimination.

In studying these cultural refigurings, Chicana Sexuality and Gender: Cultural Refiguring in Literature, Oral History, and Art focuses on two distinct groups: Chicana writers and artists, who constitute a professional intellectual class, and other working-class and semiprofessional women whose oral narratives of their own lives collected by the author are analyzed along with the writing and visual representations of the professional intellectuals. To accomplish this Blake employs Michel Foucault's concept of residual countermemory. Following George Lipsitz's use of countermemory, Blake positions the narratives of these women as "the local, the immediate, and the personal" that builds out toward the total story, even though the total may never be fully known. Such narratives, Debra Blake argues, check the impulse to valorize a single unifying story and reveal the buried histories not written into the dominant discourse. She demonstrates how for both groups this cultural refiguring arises from the interrelated processes of revising history and recovering memory. In brief, the women follow the example of "the woman of discord" by disrupting the dominant discourses that have constructed these icons.

This meticulous interdisciplinary study reaffirms the importance of recognizing the diversity within a single culture, and accepting that socalled unitary symbols inspire diverse practices. 

Debra J. Blake

\section{CHICANA SEXUALITY AND GENDER}

Cultural Refiguring in Literature, Oral History, and Art

DUKE UNIVERSITY PRESS Durham and London 2008 
(C) 2008 DUKE UNIVERSITY PRESS

All rights reserved

Printed in the United States of America on acid-free paper $\infty$

Designed by C. H. Westmoreland

Typeset in Scala with Meta display

by Keystone Typesetting, Inc.

Library of Congress Cataloging-in-Publication Data appear on the last printed page of this book. 